\title{
FIGURAS DO CONSTRANGIMENTO: AS INSTITUIÇÕES DE ESTADO E AS POLÍTICAS DE ACUSAÇÃO SEXUAL
}

Camila Fernandes ${ }^{1}$

${ }^{1}$ Universidade Federal de Juiz de Fora, Programa de Pós-Graduação em Ciências Sociais, Juiz de Fora, MG, Brasil

\section{Introdução}

Este artigo analisa a produção de determinadas políticas de acusação sexual presentes no interior de instituições de Estado. Estas políticas dizem respeito à veiculação de discursos, atos e práticas que contribuem para a gestão de conflitos, recursos, direitos, bens e serviços que chegam à população. A discussão é parte da etnografia realizada em creches públicas situadas nos morros da Mineira e do São Carlos, um complexo de favelas pertencente à Zona Norte da cidade do Rio de Janeiro. A partir da observação cotidiana das práticas profissionais realizadas nessas instituições, e também da população que busca acessar o serviço, procuro demonstrar como se arquiteta um discurso de acusação e responsabilização em torno de uma sexualidade feminina "errada" e "irresponsável". ${ }^{1}$

Durante a pesquisa de doutorado, estava interessada nas dinâmicas de circulação de crianças tal como formuladas por Claudia Fonseca (1995). Em seu estudo, realizado em bairros populares de Porto Alegre, a antropóloga descreve as maneiras pelas quais uma criança pode participar de múltiplos lares ao longo de uma trajetória de vida. Para compreender os circuitos de cuidado, acompanhei a rotina de trabalho realizada por profissionais que atuam em creches públicas, assim como a das casas de mulheres que "tomam conta" de crianças na vizinhança. ${ }^{2}$ Além destes espaços, circulei entre grupos de sociabilidade na favela e conversei com gestores de programas sociais, buscando ouvi-los sobre os problemas que mais atingiam o cotidiano do complexo do São Carlos. Nestes trânsitos, havia uma assertiva constantemente reificada não apenas nas instituições, mas também por alguns moradores 
de que os serviços públicos, as "políticas do governo" não funcionam bem porque "essas mulheres transam muito e não param de fazer filhos". Frases como "Elas dão pra qualquer um", "têm filhos de forma inconsequente", "não planejam a gravidez" eram evocadas e utilizadas para identificar a geração de uma demanda excedente e de atendimento impossível. Mulheres que "fazem filhos demais" eram apontadas como causadoras de inúmeros problemas e conflitos.

Desta forma, uma série de dificuldades que atingem a favela são evocadas em alusão à sexualidade feminina. Ao tematizarem sobre o tráfico, a violência ou a dificuldade em acessar determinados serviços sociais, tais como uma vaga na creche pública, uma consulta na Clínica da Família, ou um leito na UTI do Hospital da região, as pessoas indicavam que tais serviços são precários porque "tem muita gente pra atender", ou que a violência na favela está associada ao comportamento de mulheres que não sabem se controlar. Um suposto contingente de pessoas feitas em excesso, ou seja, "muitos filhos", estaria relacionado ao tipo de sexualidade praticada por mulheres pobres, negras e moradoras da favela, as quais, segundo os interlocutores, "não se planejam para ter filhos", "fazem um filho atrás do outro" e "gostam de viver de Bolsa Família". Mulheres moradoras de favela teriam "muitos filhos" porque "sempre tem alguém pra criar as crianças que elas têm". Afirmações deste tipo se somavam a outras passagens, nas quais mulheres pobres são evocadas como dotadas de uma sexualidade desregrada, compulsória e exagerada.

Assim, um tipo de "sexualidade errada" estaria na origem dos problemas sociais. A explicitação sistemática e a enunciação pública destes discursos convidam a levar a sério o fenômeno que diz respeito às múltiplas formas pelas quais certos problemas da "política pública" acionam justificativas que aludem a uma sexualidade feminina poluidora e perturbadora, dotada de agência especial. Como propõem Vianna e Lowenkron (2017), trata-se de acompanhar o "duplo fazer do gênero e do Estado" no contexto de uma política pública a partir de um ponto de vista etnográfico. Neste campo, a presença de uma "política da acusação sexual" é notável nas formas do "Estado em ação" e suas administrações (Teixeira \& Souza Lima 2010; Aguião 2014; Vianna 2013). Veremos, a seguir, como esta política incide na gestão dos recursos públicos e se constitui como elemento fundamental no cotidiano de uma instituição governamental, a creche. 


\section{As creches públicas}

Um dos espaços privilegiados para imersão nesta teia de acusações acerca da sexualidade e das responsabilidades femininas são as creches. Quero enfatizar que a creche pública é um bem escasso. Isto significa dizer que este espaço institucional, lugar de encontros e pessoas, de bens e serviços, de práticas e ações, não se encontra disponível para todas as pessoas e somente um pequeno contingente da população consegue acessar este bem, um "bem de cuidado" (Vianna 2002). ${ }^{3}$

Creches são instituições cruciais na provisão de cuidados. Trata-se de dispositivos ofertados pelo Estado através da Secretaria de Educação da Prefeitura do Rio de Janeiro. Tais entidades possibilitam a mobilidade dos familiares para trabalho, estudo, lazer ou tempo livre. A creche é também uma instituição na qual se vivem e se encenam muitas normas, sendo um espaço considerado como de excelência, tanto pelos usuários dos serviços como pelos profissionais que nela atuam, ainda que atravessado pela escassez e pela precariedade que perfazem o serviço público (Ferreira 2015; Leite Lopes 2016). A partir das falas, dos gestos e dos atos dos profissionais, a "instituição" ganha corpo e se realiza perante seu público, da maneira posta por Vianna como um "centro exemplar": "nunca plenamente atingido, mas também nunca totalmente desacreditado do Estado ou da lei como deveriam ser" (2013:18).

Na temporada de pesquisa em algumas creches, acompanhei a batalha por uma vaga na instituição como um dos elementos mais marcantes na vida dos meus interlocutores. Conseguir uma matrícula em uma creche pública significa, entre outras coisas, ter a garantia de que seu filho será estimulado, alimentado, arrumado, em suma, que haverá todo um conjunto de fazeres que estão compreendidos nos termos do "tomar conta" ao longo de um extenso período de vida (cerca de quatro anos). ${ }^{4}$ É um tempo que tornarão possíveis certas realizações futuras, como, por exemplo, iniciar um estudo, formar-se, montar um negócio próprio.

Habitar esta instituição significa que outros recursos poderão ser agregados sem tantas dificuldades, como acompanhamento médico na Clínica da Família, vacinação ou algum tratamento específico, como fonoaudiologia ou ortopedia. Tanto os familiares como as crianças poderão ter acesso e receber orientações relativas a benefícios sociais, encaminhamentos preciosos para este ou aquele serviço público ou de instituições não governamentais, informações sobre teste de DNA, acesso a cursos de profissionalização ou outras necessidades. Estar na creche compreende também um conjunto de mãos e corpos que irão prover atenções e afetos. Potencialidades serão desenvol- 
vidas, hábitos adquiridos, sem contar os laços de amizade e conhecimento que se tecem a partir do convívio na instituição e que podem se converter em ajudas e suportes múltiplos. Não é por acaso que em todas as eleições o tema das creches seja uma das principais pautas de propaganda e disputa política - uma causa que alavanca votos e entusiasma campanhas eleitorais, presente tanto na retórica dos partidos de "esquerda" como de "direita".

Agregar funções, estabelecer horários e temporalidades, eleger documentos prioritários, criar critérios múltiplos e essenciais, evocar as normas que importam: uma série de procedimentos e processos de regulação estão aqui reunidos, materializando a ação de uma instituição. A creche opera, desta maneira, no rebuliço destas práticas que, ao mesmo tempo em que constituem o fazer político delimitador de certas fronteiras, colaboram para a produção do Estado como estrutura metafísica, entidade autônoma, ideia-nação, aparato de indivíduos, como desvela Timothy Mitchell (2006) nas considerações sobre um "duplo efeito de Estado". O autor parte das contribuições de Philip Abrams (1988) sobre a necessidade de analisar de maneira distintiva o Estado como ideia e o Estado como sistema de práticas. Neste sentido, a creche, como um "Estado que funciona ao lado das casas", está para além da distinção entre dois âmbitos autônomos, mas é lócus privilegiado para acompanhar o que este "Estado" produz como alteridade; neste caso, nos referimos ao conjunto de práticas exercidas pelos profissionais que, ao conduzirem a execução da política pública, produzem enquadramentos sobre o que seria um excesso sexual e social atribuído ao público que a instituição recebe.

\section{O pedido de uma vaga no "sistema"}

A creche funciona a partir de um regime fechado de acesso. Por regime fechado quero dizer que, para usufruir dos benefícios ofertados pela creche, os familiares devem ser sorteados via um processo de inscrições que é realizado uma vez ao ano. A primeira fase é composta da inscrição via internet no site da Prefeitura. Posteriormente, a pessoa em busca da vaga deve comparecer à creche e "confirmar seus dados". A última etapa consiste em aguardar o resultado do sorteio. $\mathrm{O}$ acesso à creche desvela como os processos de Estado, com base em suas administrações, se relacionam com as demandas da população que vive nas periferias urbanas. Narro aqui uma cena relativa ao pedido de uma vaga como forma de evocar os diversos momentos que fazem o cotidiano de uma instituição pública. 
Em frente ao portão de uma das unidades que acompanhei há uma espécie de banco de concreto que se estende até um bar colado à instituição. Neste espaço, assisti a cenas variadas e ouvi diversos pedidos de vagas para entrar na creche, bem como várias recusas e negativas: "não tem vaga", "tem que aguardar o período de inscrição", "é por sorteio", "infelizmente não tem". Até quando as pessoas já conhecem "o sistema" e seus critérios, ainda assim elas comparecem à instituição à procura de uma brecha, uma novidade ou um imponderável que possa se desdobrar em um acesso à matrícula.

Em um dia comum, eu estava sentada neste banco externo na companhia de uma profissional da creche, ${ }^{5}$ e as pessoas que chegavam à procura de informação sobre as vagas acabavam sendo atendidas neste espaço de uma maneira "informal" que se configurava como formal. Uma mulher chamada Albelina veio até nós, logo após uma chuva forte. Tinha o cabelo preso com alguns fios úmidos e desalinhados sobre a face, vestia uma blusa de botões presa na cintura por uma saia longa e plissada que beirava os tornozelos. De um lado, sustentada por seu braço, uma criança de cerca de 1 ano de idade, toda feita de dobrinhas, se acomodava em seu colo. No outro lado, pendurados em seu antebraço, estavam uma pequena sacola e o guarda-chuva, agora fechado, que pingava. Descrevo suas vestimentas e sua corporalidade a fim de evidenciar a situação de nítida fragilidade que ela exprimia. Ela chegou até nós e iniciou um pedido à funcionária da creche:

- Oi, tudo bem?

- Tudo bem.

- É que eu preciso de uma creche pro meu filho. Eu preciso de um lugar pra deixar ele... Meu marido tá internado no hospital. Eu tô na casa da minha sogra, eu vim de Minas, eu não posso ficar com ele... Porque tenho que ficar com meu marido que tá doente, também não posso trabalhar... Uma tia dele tomava conta dele pra mim, mas ela foi embora, voltou pra Minas, a avó já ficou um pouco, mas ela tem as coisas dela pra resolver, meu marido está com câncer no estômago e não dá mais pra operar.

- Não temos vagas agora, você tem que esperar o período da inscrição ou vir aqui na segunda-feira pra falar com as diretoras e colocar seu nome na lista de espera, temos mais de 150 crianças na lista de espera, mas vem.

- É que eu não tenho com quem deixar... A casa da minha sogra tem escada, tem mofo, não é um lugar bom pra ele que tem alergia... 
- Olha, tem umas casas aqui da vizinhança de pessoas que tomam conta, você poderia tentar ver nessas casas. Tem um preço que dá pra negociar. Tipo R\$ $100, \mathrm{R} \$ 150 \ldots$

- Mas eu não tenho dinheiro, eu não tô trabalhando, o único dinheiro que a gente recebe é do Bolsa Família.

- Infelizmente é só isso mesmo, porque não tem vaga, volta aqui na segunda, volta pra falar com elas.

- Tá bem, tá certo, muito obrigada. Vou voltar na segunda, falar com a diretora...

Destaco este fragmento de diálogo para pensar na estrutura do pedido e da recusa que são partes da relação das pessoas com os serviços ofertados pelas administrações de Estado. Ao presenciar o cotidiano na creche, pude acompanhar dezenas de pedidos como este e igualmente dezenas de recusas e de portas que se fechavam. Albelina chega com um pedido: por uma vaga na creche para o seu filho. Conta sua necessidade a partir de uma "história": ela é migrante, vive na casa dos familiares do marido, os parentes não podem mais ajudar no "tomar conta" da criança, seu esposo está enfermo, precisando de cuidados enquanto paciente com câncer. Albelina pede ajuda, ela precisa de uma vaga para conseguir ajudar sua família, talvez arrumar um emprego ou conseguir cuidar dos outros.

A profissional sentada à sua frente não tem como oferecer uma vaga, pois "o sistema é fechado". Na impossibilidade de incorporar seu pedido ou criar uma brecha, finge que é uma pessoa comum, se faz de qualquer uma, pede para ela voltar outro dia, mesmo sabendo que a resposta será idêntica. A profissional sugere que ela volte para colocar seu nome em uma "lista de espera", junto com cerca de 150 crianças que ali estão registradas.

Diante do primeiro "não", Albelina continua. Sua "história" importa e precisa ser enunciada. Ela apela assim para diversos registros de linguagem e agência, em uma expressão semelhante àquilo que Luc Boltanski e Laurent Thévenot (1991) elaboraram como "ordens de grandeza", ou seja, guias práticos a que os atores recorrem para justificar suas necessidades, escolhas e situações específicas. Primeiramente, Albelina aciona a ordem da segurança: a presença das escadas e do mofo na sua casa. Em seguida, o registro da doença e da necessidade de cuidar dos outros: seu marido tem câncer e está no hospital. Depois, argumenta assinalando a sua mobilidade e a situação trabalhista: ela está desempregada e não tem como procurar trabalho. Segue lembrando que é usuária de um benefício social e, portanto, está em situação de vulnerabilidade econômica: ela só tem o Bolsa Família. 
Porém, nenhuma destas alegações discursivas consegue fissurar o sistema blindado: "o sistema é fechado". Albelina talvez não volte na segunda-feira e, se por acaso voltar, a resposta será a mesma.

A partir destes "fragmentos", vividos tal qual Maria Gabriela Lugones (2012) descreveu em sua pesquisa nos tribunais de infância de Córdoba, na interação dos "lados do balcão" - em nosso caso, nos bancos, nos degraus da instituição, nas salinhas das diretoras e professoras, na cozinha, nos corredores - fui vivenciando estas cenas e estes diálogos que fazem a rotina da instituição - cenas, momentos, expedientes e ações que permitem descrever o chamado "Estado em ação" e verificar tanto o nível das relações interpessoais que se tecem e que produzem seus respectivos efeitos como o chamado plano simbólico, abstrato ou relativo às ideias que emanam de tais práticas. ${ }^{6}$

Em outra oportunidade, pude acompanhar o ato da inscrição presencial durante cerca de dez dias, período em que os interessados devem comparecer às unidades. A fim de ajudá-las, as profissionais deixaram que eu atendesse as pessoas, dizendo que aquela era "uma das semanas mais estressantes do ano". Ao acompanhar o preenchimento das fichas, pude conversar com as pessoas que chegavam para realizar inscrição. Nessa ocasião, vi o atendimento de muitas mulheres, mães, avós, filhas, tias e sobrinhas. Somente dois homens, ao longo de todo o período de inscrição, compareceram. Uma das histórias que ouvi ao participar desse processo foi particularmente dramática: tratava-se de uma "mulher de bandido", como foi apontada por outras pessoas assim que ela saiu. Rita contava que queria muito a vaga porque não aguentava mais apanhar na frente do filho, "se ele ficar aqui, pelo menos não vai ver o pai me espancando"; o rapaz batia com qualquer coisa, tijolo, pedaço de pau, cano de pistola. Durante o preenchimento da ficha, seu filho estava sentado em uma das suas pernas, que se agitavam freneticamente para cima e para baixo no intuito de entreter o menino com o movimento de sobe e desce. Enquanto contava sua "história", emocionou-se muito.

Entre frases ditas no corredor onde estávamos sentadas, ela revelava um desespero emudecido que causava espanto, mostrava discretamente as cicatrizes pelo corpo, as lágrimas descendo em silêncio, sua boca ainda apresentando o roxo de um hematoma recente. Estávamos sentadas em cadeiras pequenas, de tamanho infantil, situadas em um corredor e separadas por uma mesa igualmente diminuta. Ali, no espaço improvisado, feito na gambiarra, no meio da passagem onde pessoas transitavam para lá e para cá, sua história era partilhada. Ao ouvir Rita, senti sua aflição e fui tomada por uma angústia tremenda, que crescia a cada momento e me deixava cada vez mais nervosa. Tentava reagir com alguns poucos recursos, dizia que era preciso procurar ajuda, ir à delegacia de mulheres, procurar um abrigo, entre outros 
dispositivos, "você não pode mais passar por isto!". Eram frases que vinham da minha boca no desespero de estar face a face com a vulnerabilidade e a violência iminente. Rita estava sendo espancada, e o último episódio era visivelmente recente. Quanta revolta isto me provocava! Entretanto, sua fala me fez entender que para "mulher de bandido" não existem instituições ou serviços capazes de oferecer proteção. A polícia não iria subir o morro para prender um bandido acusado de violência doméstica e, se assim fizesse, ela teria que prestar contas aos amigos de seu marido, parceiros no tráfico. Ela não tinha uma rede de parentesco em outra localidade que pudesse abrigá-la. Ela estava sozinha e não tinha a quem recorrer. A vaga para seu filho era uma possibilidade, um chão mínimo a partir do qual, caso o conquistasse, talvez pudesse pensar em outras estratégias de ação.

Em outro momento, acompanhei a forma com que um casal de "classe média" chegou até a unidade para solicitar uma vaga. A categoria "de classe média" era utilizada pelas profissionais e servia para aludir a algumas famílias que procuram o serviço da creche e são interpretadas pelas profissionais como "estes aí, gente que não precisa". Essa "gente que não precisa" são pessoas que se diferenciam em função de alguns marcadores, como morar em apartamento no asfalto, fora do morro, possuir um "carro do ano", ou ter alguma formação universitária, não importa qual, se pública ou privada. No ato da inscrição, ao saber que se tratava de um sorteio, ambos começaram a questionar a diretora sobre o número baixo das vagas. Diziam que a vaga era um "direito da família e da criança" e que, como tal, deveria ser garantido. Contestavam o modelo do sorteio ao mesmo tempo em que contavam sobre suas dificuldades financeiras: como jovens estudantes de universidades públicas, não tinham dinheiro disponível para pagar uma creche privada, nem familiares por perto para ajudar. A creche se apresentava como única solução.

Laura, diretora da unidade, ouvia os dois extremamente atenta. Deixava-os falar, transparecendo muita tranquilidade e compreensão. Nessas situações, ela geralmente procedia desta maneira, concedia o momento em que os outros podiam falar livremente, com uma espécie de serenidade do burocrata que conhece a minúcia do pleito daqueles que demandam, enquanto demonstrava a capacidade de se afetar. Laura parecia estar à vontade e deixou o casal falar sem qualquer interrupção. O casal citava inúmeros casos, leis e passagens argumentativas, bem como os detalhes de suas necessidades específicas. Após ouvir pacientemente toda a fala do casal sobre "os direitos" e os "absurdos" da política pública, Laura inspirou fundo, colocou as mãos na cintura e engatou uma verdadeira oratória na qual demonstrou, de maneira didática, que todo o discurso dos direitos simplesmente de nada adiantava. 
De uma hora para outra, seu semblante empático deu lugar a uma postura imponente; agora ela falava para todas as pessoas presentes e, uma vez com a palavra, esta era toda dela: "olha, deixa eu perguntar uma coisa, por que vocês não esperaram pra fazer filho no tempo certo?". O casal emudeceu, as pessoas à volta olharam, e ela seguiu: "não adianta falar que é direito, porque não tem vaga!". O casal, atônito, permaneceu durante um tempo sem reação, como alguém que percebe estar diante de uma realidade intransponível, na qual "não tem jeito", "nada vai adiantar". Um pouco de vergonha começou a despontar na expressão dos dois. Buscaram ainda outros argumentos, mas agora o discurso era todo de Laura: "o Estado não tem essa obrigação, de ter que fazer creche pra todo mundo. Se você queria ter filho, por que você não pensou em quem ia criar, se ia ter dinheiro? Mas ninguém pensa nisso, não é?".

Nesses momentos Laura é dona de um tom professoral, sua voz é encorpada, melódica e enérgica. Esta postura chamou a minha atenção para um aspecto das administrações, a saber, a habilidade de falar para um e ao mesmo tempo falar para todos que estão no entorno, numa espécie de performance pública que consiste em transmitir uma lição para a coletividade. Tais cenas são uma espécie de "esporros" públicos que fazem parte de uma pedagogia do constrangimento muito própria das administrações. Observei que outras funcionárias também acionavam este proceder. Em geral, elas iam muito além de dizer "não", derramando uma oratória para quem estivesse no ambiente, que continha sempre uma lição moral, um discurso capaz de convencer qualquer pessoa de que não importava qual fosse sua teoria crítica elaborada em face do serviço oferecido. Na situação de escassez de recursos estatais, Laura sabe aplicar essa espécie de prática da contenção e desmontar, a partir de uma "alternativa infernal" (Pignarre $\&$ Stengers 2013), todo e qualquer discurso de direitos.

Pignarre e Stengers (2013) desenvolvem a ideia de "alternativas infernais" para aludir a situações nas quais a ação pública se apresenta através de uma série de alternativas ou opções quase sempre insatisfatórias e ruins. Estas situações de poder produzem um efeito de paralisação e resignação nos sujeitos e, não importa o que aconteça, as pessoas se veem em circunstâncias nas quais "não tem jeito", nada vai adiantar, quer seja o protesto, a denúncia ou a procura de outras soluções. É, em si, um mecanismo de esvaziamento da ação política, uma vez que reduz as possibilidades de agência e trânsito dentro do "sistema", neste caso, dos dispositivos de entrada na política pública "creche" oferecida pelo Estado. Naquele dia, o casal foi embora visivelmente desconcertado. 
A incapacidade das profissionais em oferecer outras alternativas diante destas situações acaba por produzir um "esfriamento" naquelas que deveriam ser as transmissoras das negações e das impossibilidades. Com o passar do tempo, observei que o automatismo das respostas, a opacidade dos pedidos e a naturalização das densidades das histórias que ali são contadas fazem parte da rotina administrativa com que estas profissionais devem lidar. Elas relatam o quanto devem ser "frias", porque "precisar, todo mundo precisa". Chamo a atenção sobretudo para a forma como o "dizer não", necessidade com a qual as profissionais se veem confrontadas em sua prática cotidiana, produz uma situação de desigualdade flagrante entre mulheres pobres e outras não tão pobres, porém em situação similar àquela de serem batalhadoras. As profissionais cujas práticas narro aqui são moradoras de subúrbios, baixadas, periferias e áreas pauperizadas da cidade, algumas são nascidas e criadas em favelas, outras até hoje são moradoras de favelas e periferias; todas lidam com os problemas de outras mulheres pobres e faveladas.

Entretanto, ao falar em "esfriamento", quero detalhar que esta "frieza" é de uma natureza curiosamente distinta da acepção do termo "frio". Não se trata de posturas distantes ou indiferentes, de tal modo que a sensação de incapacidade em atender o outro permanece sob a forma de um verdadeiro incômodo e afetação permanente. Esta frieza é apenas a superfície de uma chama profunda que oferece as bases para a elaboração de visões sobre o outro, fomenta a produção dos apontamentos e das acusações que, por sua vez, fornecem discursos sobre uma teoria da justiça, da preguiça, da pobreza e do comportamento sexual excessivo, atribuídos à favela enquanto território.

Nesse movimento cabe perguntar: em que momento a empatia em relação a uma "história" se transforma em acusação sobre a preguiça e a incapacidade dos outros? Observei como profissionais da administração podiam evidenciar ao mesmo tempo uma profunda solidariedade com os pedidos que ali chegavam e um sentimento enérgico de revolta com "a preguiça dos pobres". A passagem da compreensão para a revolta quanto aos outros era questão de minutos. Quando falo em empatia, não me refiro a meras estimas pessoais e fugazes, mas sim de muitas situações nas quais as profissionais tentavam ajudar de fato e buscavam soluções para problemas que estavam "fora da alçada" delas. É justamente nesse contexto intenso e diário que as narrativas e os discursos em torno do "sexo que faz filhos" formam um caldo espesso e fecundo para explicar a impossibilidade da política pública de atender à sua demanda. Explicam como a sexualidade das mulheres é "errada" e provoca coisas negativas. Estas narrativas, que operam através da linguagem e do discurso, são feitas num misto de empatia e dureza da 
"realidade", a exemplo do encaminhamento dado ao casal de estudantes que pleiteava uma vaga com base na narrativa dos direitos, mas foi enquadrado como pessoas que não esperaram para ter filhos no "tempo certo".

De volta às inscrições, o dia da divulgação dos resultados do sorteio é um momento extremamente caótico. Durante os dois anos de pesquisa, havia em cada unidade uma lista de espera de mais de 200 crianças. A lista é fixada geralmente na recepção de cada creche e lá permanece durante o ano inteiro. Na verificação da lista, a maioria daqueles que se inscreveram recebe a notícia de que não conseguiu a vaga. Pessoas lamentam, choram, brigam, discutem, reclamam e querem satisfações. Alguns saem de cabeça baixa, absolutamente desolados, conversando com parentes que os acompanham: "o que a gente vai fazer agora?". Outros protestam, não entendem "o sistema", não aceitam.

Eis que alguns começam a "fazer um barraco" na recepção da creche: gritam, falam alto, ameaçam, gesticulam, colocam no chão objetos que seguram e as crianças; precisam das mãos livres para protestar. Nesse momento, as profissionais diminuem o tom, apenas ouvem constrangidas, respiram fundo, tentam responder calmamente. Algumas mulheres ameaçam as profissionais, dizem que, se a vaga do filho não for concedida, vão "falar com os caras". Sentenciam, num tom poderoso que dá o futuro por certo, "ah, meu filho vai ter vaga aqui sim! Ah, se não vai!", seguido de risadas raivosas.

Depois do calor público que inflamou o ambiente durante o "barraco", as pessoas conseguem algumas orientações preciosas e estratégicas, como ir na $1^{\mathrm{a}} \mathrm{CRE}$ ou procurar o Ministério Público para dar entrada em um processo de garantia da vaga. Desta maneira, algumas famílias, em geral as mães, seguem a peregrinação burocrática na busca da obtenção de uma vaga. ${ }^{7}$ É então que surgem na imprensa algumas matérias de cunho sensacionalista que todos os anos noticiam o mesmo: as filas homéricas de crianças que não conseguiram vagas. ${ }^{8}$

A dimensão da "sorte" envolta na concepção frágil de um "direito" supostamente universal, "o direito à educação", é um lugar eminente de double bind (Bateson 1972). O duplo vínculo descrito por Gregory Bateson fala de situações nas quais o emissor da mensagem transmite uma comunicação plena de sentidos contraditórios ou ambíguos. Nelas, o receptor da mensagem se encontra em uma realidade na qual não é possível ganhar e o que resta é habitar a própria circunstância de ambiguidade e angústia imposta pelo "sistema". Quando a política pública se apresenta ao mesmo tempo como um direito universal e com critérios exclusivos de acesso e "sorte", traduzidos em diversos atos cotidianos de poder, estamos diante da tradução política do conceito do autor. Trata-se de duas mensagens absoluta- 
mente contraditórias: preconizar que a educação é fundamental para todos, que a criança é "sujeito de direitos", mas deixar um contingente expressivo de crianças fora da política, na "lista de espera".

Nesse sentido, é importante explicar que a entrada na creche se faz a partir de três maneiras distintas de acesso à política pública. A primeira se realiza com um "sorteio público", no qual, a princípio, toda pessoa pode concorrer. A segunda forma se apresenta como um desdobramento da primeira, porém envolvendo o acionamento de critérios assistenciais de vulnerabilidade que visam qualificar os sujeitos que apresentam maior prioridade/ necessidade de acessar uma vaga. Este procedimento de verificação dos critérios é feito pelas profissionais da direção nas unidades das creches. ${ }^{9} \mathrm{~A}$ terceira se dá pela via normativa e do Direito e pode ser acionada nos casos em que os familiares recorrem à Justiça. Desta maneira, em um contexto de pobreza e disparidade de recursos, tais critérios acabam por gerar rumores e fofocas no decorrer do processo de inscrição, mas não somente, pois se transformam em diversos juízos e interpretações produzidos no conjunto de afirmações do cotidiano popular sobre "quem precisa mais", "quem fez filho na hora certa", "que mãe que trabalha", "quem é vagabunda", "quem conseguiu vaga, mas passa o dia na praia e chega aqui bronzeada", "quem fez tudo certo, na hora certa e ficou de fora", "por que fez outro filho, se já tinha um?".

Uma vez que as pessoas sabem que narrar as suas próprias vulnerabilidades no processo de acesso às vagas importa, elas buscam mobilizar seus sofrimentos porque entendem que esta situação pode fazer diferença no sorteio das vagas no "sistema". Porém, cabe destacar que, independente de uma apreciação de cada necessidade de uma ou de outra família, o resultado final da distribuição das vagas fica muito aquém da demanda por elas em creches públicas, conforme explicitado nas matérias de jornais citadas.

Outro fato é que a grande maioria das crianças concorrentes se encaixa em ao menos algum dos critérios de vulnerabilidade estabelecidos pelas administrações. Diante deste quadro, as famílias se questionam, ao final do processo, se esses critérios são eficientes, se eles "realmente funcionam", se vale a pena dizer que tem um "parente presidiário" na família, se isto "conta mais" do que alguém "doente", por exemplo, de o "porquê [de] uma mãe de 22 anos precisar menos do que uma mãe de 16 anos". Daí que muitas pessoas que acompanhei preferirem simplesmente "dizer a verdade" da sua situação, não porque tais realidades sejam "mentiras", mas por conhecerem exemplos de parentes e vizinhos que, em experiências anteriores de tentativa de obter uma vaga, elencaram uma série de dramas e relatos pessoais que pontuavam necessidades específicas e ainda assim não conseguiram a vaga. 
"Dizer a verdade" remete ao reconhecimento de que, independente da estratégia utilizada pelas famílias, o número de vagas oferecidas pelo "Estado" será sempre insuficiente em face da demanda da população. As famílias se veem diante de um "sistema" com pouca margem de ação. Finalmente, é o critério da "sorte" que se apresenta como um operador de recorte aleatório diante deste esquema repleto de nuances de suplício e vulnerabilidades.

\section{O distúrbio e a "desordem" dentro do centro exemplar}

Se uma casa é um espaço de difícil administração devido às inúmeras urgências que brotam nela, faz sentido pensar que a creche é uma hipérbole da casa. Não são levianas as passagens em que muitas profissionais entoam enunciados do tipo "isto aqui é como uma família", em frases que apontam para a dimensão familiar indiscutível da instituição. Estamos, pois, diante das entranhas afetivas, morais e de parentesco constitutivas de nossas instituições públicas.

Numa creche, tal como numa casa, tudo acontece e deve ser resolvido. Acompanhei o acúmulo de tarefas, a exaustão, a rotina e a multiplicidade de deveres que as profissionais devem superar. Elas realizam trabalhos que, até pouco tempo atrás, "não faziam parte da obrigação", como fiscalizar as presenças das crianças para alimentar os dados do Bolsa Família e do Cartão Carioca, verificar quais crianças não têm o "nome do pai" na certidão de nascimento, convocar suas mães à creche para oferecer esclarecimentos quanto a possíveis encaminhamentos ao programa "Pai Presente", entre outras demandas que chegam e que exigem fiscalização, registro burocrático e um tempo considerável da ação de trabalho. "Tudo vem lá de cima", como me explica uma profissional ao dizer que as decisões são tomadas por instâncias superiores e que nenhuma delas inclui a sua participação, que atua "na ponta", como todas as demais. Este é um proceder que faz parte daquilo que Herzfeld chama de uma "teodiceia secular", "meios sociais para as pessoas lidarem com a decepção" (1992:7), em que a burocracia se desdobra em seus aspectos metafísicos e religiosos, como algo que vem do "alto", que remete a um mundo superior e desencarnado, que não se vê, mas no qual se deve acreditar.

No âmbito da alimentação, a cozinha da creche tem uma das atividades mais exigentes na ação do "tomar conta", que diz respeito ao trabalho das antigas "merendeiras" e atuais "auxiliares de cozinha". É possível que o nível máximo de precarização e doenças de trabalho se encontre aqui, na ação das mulheres que se dedicam a cozinhar, alimentar e nutrir. O cargo data do ano 
de 1985 e desde os seus primórdios está envolvido em controvérsias políticas acerca de sua valorização e reconhecimento. ${ }^{10}$ Uma auxiliar de cozinha pode limpar, fatiar e picar em um dia de trabalho grandes quantidades de carne, legumes e verduras. O trabalho também consiste em manusear panelas enormes e pesadas, que servirão para alimentar as crianças e os funcionários da creche. Ademais, é importante registrar que a forma de contratação de muitas das funcionárias (tanto da cozinha quanto do setor de limpeza), através de empresas terceirizadas, envolve um alto nível de precariedade que as deixa sujeitas a toda sorte de acontecimentos possíveis ao longo do fluxo de repasse das verbas entre empresas privadas e a Prefeitura.

Observei que as diretoras de algumas unidades faziam "vaquinha" para o pagamento da internet, um serviço que "deveria ser financiado pela Prefeitura". Todos estes problemas eram de competência e responsabilidade do "poder público" e envolviam licitações não cumpridas, contratos em atraso ou dificuldades técnicas de responsabilidade das empresas de comunicação no oferecimento do serviço (por exemplo, a inexistência de cabeamento de internet em determinada favela, por exemplo). Desta forma, gambiarras e combinados informais eram tecidos com moradores locais, os "conhecidos", que se empenhavam na realização de reparos na creche. Estes serviços poderiam ser hidráulicos, elétricos, de construção, de limpeza, entre outros. Obviamente, todo este conjunto de serviços estava previamente aprovado no "orçamento da prefeitura", mas "o dinheiro nunca chega", como comentavam as profissionais. Assim, o atendimento às demandas era retardado, o que obrigava as profissionais a realizar diversos tipos de "virações" para manter o serviço funcionando.

A presença de televisores nas salas de aula é outro elemento digno de consideração, já que o recurso a este objeto é fortemente criticado quando se fala nas casas de "tomar conta": "lá, as crianças ficam largadas e abandonadas à televisão". O aparelho é utilizado pelas professoras seja na hora do descanso que se inicia após o almoço, seja durante as manhãs e as tardes, com as crianças acordadas. A maioria dos filmes disponíveis era de CDs "piratas", adquiridos em camelôs nos mercados informais.

Outro aspecto criticado nas casas "de tomar conta" é que nelas haveria "poucas pessoas para olhar as crianças". A presença de poucos adultos responsáveis seria mais um elemento para a criação das crianças "largadas". Entretanto, sabe-se que este é um dos aspectos mais pungentes na educação infantil oferecida pelo Estado: a falta de profissionais suficientes nas creches. Não foram poucas as situações em que observei que a rotina das profissionais consistia em "tapar os buracos" causados pela falta de professoras. Do ponto de vista normativo, uma sala com a presença de 25 a 28 crianças 
deve contar com a permanência de dois professores e dois auxiliares. Nas creches que acompanhei, esta configuração raramente ocorreu. Em geral, nas salas havia uma professora e uma auxiliar. A falta de profissionais tem um efeito muito prático no tipo de tratamento oferecido às crianças. Do ponto de vista humano, é impossível que duas adultas consigam "dar atenção" a um grupo de 25 a 28 crianças em sala. Muita criança para dar conta, pouco adulto para "tomar". A composição da equipe para atender às crianças é feita de muitos revezamentos e malabarismos entre mulheres, que geram, consequentemente, uma considerável sobrecarga de trabalho. Administrar esta escassez de profissionais era um dos problemas primordiais das diretoras e das professoras.

Momentos como servir a comida, dar banhos, pentear, colocar para dormir, reunir o grupo para uma roda de leituras, propor uma atividade manual ou de concentração são feitos, diariamente e repetidamente por apenas duas mulheres. Não importa quão afetuosas ou dedicadas elas sejam, já que em diversos momentos a pressão do grupo consegue vencer qualquer tentativa de organização de tarefa que requeira atenção ou concentração maior.

Outras sensações adensam os estados emocionais. Em uma das creches que acompanhei, algumas professoras se sentiam desconfortáveis durante a limpeza das crianças no berçário, diziam que era necessário o uso de luvas descartáveis para a realização da troca de fralda. Estavam munidas de uma recente normativa da vigilância sanitária que sugeria o uso deste material em situações como estas. Presenciei o desenvolvimento de brigas em torno da questão. Apesar de o uso das luvas não ser obrigatório, ele é indicado em função das sensações de repulsa, nojo ou preferência de cada profissional. No entanto, "a prefeitura não tem dinheiro" para fornecer as luvas, e o material é um artigo de luxo que sempre está em falta.

Numa ocasião, uma diretora estava em polvorosa com parte da equipe que, por sua vez, estava realizando um tipo de motim via grupo de WhatsApp para reclamar e protestar contra a falta das luvas. Fazia semanas que a diretora tentava "dar um jeito" e comprava as luvas com o dinheiro de seu próprio bolso a fim de abrandar a situação. A falta destes objetos, daquilo que "deveria ter e não tem", pode aumentar ainda mais conflitos entre as profissionais, agregando forte tensão a relações já atravessadas por assimetrias diversas.

As preocupações com a limpeza se aplicam também às peças pessoais das crianças, objetos-veículos que trazem a intimidade da família para dentro da instituição. Assim, os interiores das mochilas, bem como as peças de roupas podem ser acionados para qualificar o bom ou mau cuidado de deter- 
minada família, em especial da figura materna. As profissionais discorrem sobre o "desleixo" de algumas mães a partir da presença destes atributos. Em tais situações, muitas vezes as profissionais criticam o zelo "excessivo" das mães com o cabelo dos filhos, uma preocupação, na perspectiva delas, aparentemente fútil quando comparada à apresentação de outros objetos e vestimentas das crianças. Assim, é comum ouvir frases como "a mochila tá uma zona, mas o cabelo! Ah, tem que tá arrumado! Experimenta entregar uma criança despenteada pra você ver. Elas vêm com tudo em cima de você". A atenção "excessiva" à aparência dos cabelos, em contraposição ao cuidado supostamente não ofertado pelas mães aos objetos das crianças, é uma das preocupações que falam de relações raciais a partir dos penteados dos/as filhos/as, pois desvela estigmas que vinculam cabelo, estética, origem, negritude a qualidades negativas, tais como "bagunça" e desordem.

A avaliação dos cabelos das crianças articula gênero e raça. Se, por um lado, as "mães fazem questão [de] que o cabelo esteja arrumado", é porque este atributo exibe os sinais diacríticos do cuidado, da limpeza, do respeito e da pessoalidade. Por outro lado, as profissionais criticam essa preocupação materna "excessiva", que indica futilidade das mulheres na atenção a este quesito, em contraposição ao cuidado que elas deveriam ofertar em suas casas, apontando as mochilas "sujas" e as roupas íntimas "largadas".

Na perspectiva das mães, a cobrança do cuidado com os cabelos constitui um veículo que permite exigir e avaliar o carinho, o zelo e o bom tratamento oferecido às crianças, porque são elementos de reconhecimento e dignidade. Na narrativa das profissionais, o cabelo adquire o status de contra-acusação, pois permite cobrar dessas mulheres algo que elas supostamente não fazem e que deveriam fazer: a responsabilidade materna e inalienável com os filhos. O cuidado com os cabelos na instituição é um elemento de fogo cruzado, um articulador que revela as diferenças raciais e de gênero que transbordam das paredes institucionais no que diz respeito às leituras raciais entre crianças "negras" e de cores "misturadas". Uma leitura prenhe de qualidades morais e afetos distribuídos de maneira diferenciada, ao expor cabelos "difíceis" e "fáceis" de serem penteados, em valorações raciais vividas na miudeza e na intimidade nem sempre enunciadas publicamente.

\section{Um Estado feminino}

No exame da ação das profissionais da Justiça nos Tribunais de Córdoba, Lugones (2012) observou a presença de mulheres, as "pequenas juízas" responsáveis por "levar o caso" das crianças em situações de tutela do 
Estado. Neste contexto, Lugones identificou um repertório de gênero constantemente acionado por estas profissionais: "sentir", "prever", "escutar", "ouvir" e "evitar" eram termos que apontavam para qualidades e competências repletas de um imaginário de gênero. Ao retomar o par "gestar e gerir" como posto por Souza Lima (2002), a autora possibilita o reconhecimento de uma espécie de "gestão maternal" presente nas dinâmicas tutelares próprias das práticas judiciais em contato com as "minoridades". ${ }^{11}$ É neste contexto que Lugones sugere uma figura construto, o "matronazgo", um tipo de espectro que relaciona "noções sócio-historicamente produzidas a respeito dos atributos endossados aos direitos-deveres maternos" (2012:211). A autora salienta que estes valores não estão referidos aos aspectos legais ou normativos, mas dizem respeito a "uma plataforma de crenças divididas que, embora em contínuo deslocamento, mantém traços fortes em relação ao que nos acostumamos a reconhecer como uma gestão maternal" (2012:212)

A presença e "a força das imagens maternais" desveladas por Lugones, mais especificamente da própria maternagem na gestão judicial das infâncias, permite identificar a capacidade do gênero de dar sentido, de qualificar os feitos no cotidiano de uma instituição de Estado e de salientar, por exemplo, a centralidade da categoria "prevenção", lembrando que "prevenir é também prever". As condições reunidas no ato de "prever" estariam vinculadas às intuições, ao "faro", à capacidade de rastrear um possível drama, a estas e outras características atribuídas, em geral, a uma socialização feminina.

Utilizo estas reflexões para desenvolver o argumento de que aqui, na creche, ocorre um fenômeno muito semelhante. Um Estado feminino se desvela na presença de mulheres trabalhadoras, de origem popular, que alcançaram uma situação de maior ou menor estabilidade de trabalho ao conquistarem uma posição no serviço público. Porém, estas mesmas mulheres se encontram em situação de batalha, considerando-se que são moradoras de zonas periféricas e da baixada da cidade, possuem família, muitas têm filhos e, portanto, estão envolvidas em circuitos de "tomar conta". Ao mesmo tempo, muitas se situam no lugar de figuras do constrangimento quando devem administrar a incapacidade de acolher as demandas por vagas dentro do "sistema", entre outras inúmeras faltas. Se, por um lado, elas ocupam cargos de poder ou de prestígio, como professoras ou diretoras, por outro, elas não participam dos processos de decisão impostos pelo próprio "sistema", já que "tudo vem lá de cima", incluindo decisões fundamentais ao seu trabalho.

Estas são profissionais que se encontram "na ponta" da gestão estatal e devem administrar os pedidos que chegam à recepção, as "histórias tristes" que são contadas e que abundam nas franjas da instituição, a realidade do entorno que bate à porta de maneira insistente, mesmo diante das regras 
blindadas do "sistema". No fundo, são vistas como aquelas que, de uma forma ou de outra, podem e devem "dar um jeito".

Desta maneira, são as profissionais que devem administrar a precariedade a partir de gambiarras como a "vaquinha da internet", a falta de professoras em sala de aula, a providência das luvas para a troca de fraldas, entre outros tipos de serviços e objetos custeados através dessas composições inusitadas e precárias. Elas manuseiam o peso e o custo social dos "filhos dos outros", bem como o das panelas gigantescas da cozinha que devem estar ora cheias, ora limpas e higienizadas. Este é um Estado feminino que se assenta na fragmentação das categorias hierárquicas entre mulheres, entre professoras, diretoras, agentes de educação, profissionais da limpeza e da cozinha, que se distribuem por contratos de emprego variados, com naturezas distintas e valores salariais díspares, o que instaura uma assimetria profunda entre elas.

Através da cena entre profissionais e mulheres que buscam uma vaga no "sistema" conhecemos uma retórica dotada de uma estética de gênero, que não somente incorpora as dimensões maternais mais clássicas, como prever, sentir, cuidar ou fragmentar, mas também, na luta pelos direitos, aciona metáforas maternais, a exemplo do útero e do ventre, como demonstrado por Vianna e Farias (2011), e que pode ser profundamente violenta quando se ergue a partir de um Estado feminino amoroso, que sabe ofertar afeto, cuidado e carinho às crianças, ao mesmo tempo em que sabe distribuir "esporros" públicos às famílias.

Este Estado feminino atua em meio a um contexto de operações militarizadas nas favelas e problematiza a violência policial praticada no dia a dia, enquanto guarda um aspecto violento ao exercer outras modalidades de tratamento, imiscuídas nos pequenos gestos cotidianos, nas recusas sistemáticas dadas às famílias, nas incontáveis negativas aos pedidos por vagas, na gestão contínua da falta, nos posicionamentos minuciosos sobre pessoas que "precisam mais" ou que "precisam menos", no estabelecimento de critérios de vulnerabilidade dentro de regimes pensados como "direito de todos".

Nesse sentido, resgato uma cena do cotidiano da creche, na ocasião em que as diretoras deveriam distribuir caixas de leite para serem doadas entre as famílias usuárias do serviço. Durante a entrega, duas funcionárias da limpeza, igualmente mães de crianças pequenas, estavam auxiliando na distribuição de leite e ansiosas em saber se poderiam receber os donativos. No momento de doação das caixas aos familiares, uma profissional da direção dizia com muita naturalidade: "Olha! Como adoram receber as coisas de graça!", "fica feliz recebendo leite!", "Tá vendo? Pra que se planejar pra ter filho?". 
Ao proferir tais enunciados, na presença dos familiares e profissionais de posições subalternas, uma das funcionárias reagiu com deboche e dando de ombros, e se concentrou nas caixas de leite que desejava obter. Outra funcionária permaneceu em silêncio e observou a diretora com olhar lancinante, transmitindo a evidente sensação de incômodo com tais sentenças. Não é aleatório que o discurso sobre "facilidade", "preguiça" e "falta de planejamento" ocorra durante a partilha de caixas de leite. O leite, enquanto substância potencialmente generificada, é um agente especial que "anima", tal qual formulado por Janet Carsten (2011), as operações de censura e coerção, ao simbolizar a alimentação de crianças feita por mulheres enquadradas como "irresponsáveis", "preguiçosas" e dependentes de favores.

Em "Finding the Man in the State" (1992), Wendy Brown chama a atenção para a estrutura masculinista do Estado. Tal evocação funcionaria menos como uma entidade autônoma, e sim enquanto conjunto incoerente e multifacetado de relações de poder. Nesse sentido, vemos como este Estado feminino, ao acionar um repertório de crenças compartilhadas marcadas por gênero, sexualidade e reprodução, transfigura o masculinismo de Estado e o recoloca via "dimensão burocrática do poder Estatal" (Brown 1992). O comportamento sexual e reprodutivo das mulheres usuárias da creche é destacado como eixo capaz de desregular a política pública. Tal enquadramento é utilizado pelas profissionais da creche na burocracia cotidiana da administração dos recursos públicos. A responsabilidade do cuidado das crianças é conduzida a partir de uma gestão cuidadora que deve conter a demanda gerada por mulheres em sua maioria negras, pobres e trabalhadoras que "fazem filhos demais". Além da dimensão da falta de recursos, observamos a produção e a distribuição de humilhação e vergonhas que encorpam as crenças compartilhadas sobre gênero e sexualidade feminina atualizando elementos de misoginia e racismo de Estado (Foucault, 1975-1976).

Se o poder é múltiplo e contraditório, estas cuidadoras devem gerir a escassez de recursos com base na regulação das condutas sexuais de outras mulheres, em níveis de intensa intimidade e desigualdade social. Tal modalidade de ação potencializa os dramas acerca do cuidado das crianças num contexto de disputa de mercadorias sociais, ao mesmo tempo em que, no contexto brasileiro, oblitera o debate sobre direitos sexuais e reprodutivos e reprime a frágil ideia de um "Estado provedor" voltado ao investimento em política de creches.

Estamos, assim, diante de territórios de acusação e controle, em meio a um Estado amoroso que, enquanto sabe amar, sabe também coibir. Neste contexto, discursos sobre uma sexualidade "exagerada" e "fora de hora" se constituem como um dos mecanismos de constrangimento e acusação para 
lidar com a realidade da política pública, em sua incapacidade de atender às necessidades dos outros. Entre estes polos nada estáveis de posições sociais, visualizamos a proximidade das questões que unem essas mulheres dentro e fora da administração estatal e provocam a possibilidade de empatia, a "vontade de ajudar", sem desfazer a distância social que decorre de ocuparem posições de poder assimétricas. Assim, para gerir a incapacidade de atender à demanda que chega à instituição, encontramos práticas que atualizam características comuns à feminilidade, como o acolhimento e o cuidado com as crianças que são recebidas nas instituições, ao lado de expedientes de humilhação, cobrança e responsabilização. A creche, como espaço institucional e supostamente neutro, reifica aspectos do mundo familiar articulando o cuidado e a coerção, o carinho e o castigo daqueles que dependem de sua ação. Estamos, pois, diante de um ambiente poderoso para refletir sobre as políticas cotidianas de acusação sexual com as quais mulheres pobres, negras e moradoras de favelas devem conviver.

Recebido em 11 de dezembro de 2018

Aceito em 24 de junho de 2019

Camila Fernandes é Doutora em Antropologia Social (PPGAS/MN/UFRJ) e mestre em Antropologia (PPGA/UFF). Pesquisadora do NuSEX - Núcleo de Estudos em Corpos, Gênero e Sexualidades (PPGAS/MN/UFRJ) e do LACED - Laboratório de Pesquisas em Etnicidade, Cultura e Desenvolvimento. Atualmente atua como pós-doc no Programa de Pós-Graduação em Ciências Sociais (PPGCSO/UFJF). ORCID: https://orcid.org/0000-0003-2446-1760

E-mail: fernandesv.camila@gmail.com 


\section{Notas}

1 Este artigo é parte da tese de doutorado intitulada Figuras da causação: sexualidade feminina, reprodução e acusações no discurso popular e nas políticas de Estado, defendida em 2017 no âmbito do PPGAS/MN/UFRJ e orientada pela Professora Dout. Adriana de Resende Barreto Vianna. Além da interlocução preciosa proporcionada por Adriana, agradeço as críticas e os comentários dos professores Luiz Fernando Dias Duarte, Claudia Fonseca, Maria Gabriela Lugones e Maria Elvira Dìaz-Benìtez na ocasião da defesa. Agradeço também aos comentários do grupo de orientandos formado por Lucas Freire, Telma Bemerguy, Aymara Escobar e Jeferson Scabio por todas as indicações generosas. À Professora Laura Lowenkron também agradeço por indicações fundamentais. Todas estas contribuições colaboraram para a construção deste artigo.

2 As "casas de tomar conta" são espaços comuns nas favelas e nos bairros periféricos da cidade do Rio de Janeiro. Trata-se de casas de mulheres moradoras da vizinhança que "tomam conta" de crianças em suas próprias casas. As Casas não servem apenas aos moradores do morro, mas atendem a crianças de muitos bairros vizinhos. As pessoas indicam o trabalho das Casas no "boca a boca" e, a partir desta rede de indicações informais, conhecem as Donas da Casa. Estas são mulheres que têm uma sólida trajetória de cuidados dos outros e por isto são mulheres reconhecidas na vizinhança. No geral, são mulheres jovens ou idosas que têm a possibilidade de garantir uma renda a partir deste trabalho. Algumas mulheres chegaram a cuidar de três gerações familiares. Vale ressaltar que estes espaços não recebem qualquer subsídio do governo. Além destas casas, existem outras formas de cuidado igualmente estratégicas, como mulheres que levam e buscam na creche, crianças que são provedoras de atenções ao cuidarem de irmãos ou parentes, mulheres que, em suas próprias casas, tomam conta de seus próprios filhos junto com outras crianças, filhos de uma amiga ou de uma vizinha, sem esquecer dos parentes e amigos que se ajudam na criação de outros.

3 A tese de Vianna examina o agir do Estado na gestão de menoridades através dos processos de guarda de crianças na Justiça. Vianna localiza o lugar especial dos bens de cuidado, objetos que materializam e encarnam a virtualidade do cuidar. A provisão e a doação dos bens de cuidado indicam e reconhecem os bons e legítimos responsáveis: "todos os bens de cuidado exaustivamente listados - berços, brinquedos, planos de saúde, pediatras particulares etc. - representam sinais do investimento que pode ser calculado e, ao mesmo tempo, que nunca pode ser expresso claramente em termos materiais, já que serve de indicativo da ação desinteressada que não espera pagamento imediato ou não o espera na mesma moeda" (Vianna 2002:31).

4 Na tese e em outros trabalhos, discuto de que maneira a categoria "tomar conta" se refere a um dispositivo de regulação da vida que envolve o cuidado e a coerção, bem como a proteção e a cobrança (Fernandes 2011, 2017).

5 O uso do termo genérico "profissional da creche" se dá por motivos de sigilo. Entre técnicas, professores, vice-diretores, auxiliares, entre outros profissionais, identifico o cargo apenas quando a passagem não fere este princípio de pesquisa. 
6 Refiro-me a um conjunto de trabalhos que se dedicam a analisar o chamado "Estado em Ação". A perspectiva foi aberta pelos trabalhos de Antônio Carlos de Souza Lima $(2002,2012)$ e se desenvolveu posteriormente nas análises de Vianna (2002, 2011, 2013, 2014), Ferreira (2015), Lowenkron (2015), Aguião (2014), Lacerda (2015), Lopes (2016) e Freire (2016).

7 Algumas famílias procuram o Ministério Público ou vão até a Prefeitura reclamar. Fui até o órgão responsável pelos processos de pedido de vaga e encontrei um processo da minha altura em tomos empilhados. Algumas de suas páginas traziam queixas e denúncias registradas sobre pedidos de matrícula não atendidos. Para poder utilizar as páginas do processo na pesquisa a fim de exemplificar os trâmites pelos quais as famílias passam, eu teria que fazer uma solicitação que posteriormente deveria ser aprovada pelo juiz responsável. Diante de tanta burocracia, acabei desistindo, e preferi voltar à pesquisa na favela. Entretanto, registro esse movimento para indicar a peregrinação pela qual os familiares devem passar na conquista de uma vaga, caso não sejam contemplados no sorteio.

8 Algumas reportagens registram as filas de espera para as vagas nas creches (G1 2019; Defensoria Pública do Estado do Rio de Janeiro 2018).

9 Os critérios devem ser preenchidos e comprovados a partir de documentação específica. No Rio de Janeiro, devem ser atendidos na seguinte ordem: "1) Crianças cuja família seja beneficiária do Cartão Família Carioca; 2) Crianças com deficiência; 3) Crianças cuja família esteja inscrita em algum programa de transferência de renda; 4) Crianças que estejam relacionadas na lista de espera da creche, elaborada no ano anterior; 5) Crianças ou familiares vítimas de violência doméstica; 6) Crianças ou alguém do núcleo familiar acometido por doenças crônicas; 7) Crianças com alguém do núcleo familiar que faz uso abusivo de drogas; 8) Crianças com alguém do núcleo familiar que seja presidiário ou ex-presidiário; 9) ter irmão(ã) gêmeo(a) que também está sendo inscrito(a); 10) Ser filho de mãe adolescente" (Brasil 2014).

10 No surgimento desta categoria profissional, o trabalho consistia em atividades de servir e montar pratos, os alimentos chegavam industrializados e preparados, como salsichas, enlatados e coisas do gênero. Com o passar do tempo, as normativas em relação à alimentação saudável foram chegando, e um padrão de boa alimentação recaiu na prática das profissionais. A tarefa das merendeiras passou do ofício de montar e preparar pequenos pratos para a tarefa de cozinhar alimentos em grande escala.

11 É importante lembrar de outras figuras relacionadas ao matronazgo retomadas por Lugones: "São frutíferas aqui as afirmações de Pacheco de Oliveira (1998:224) e Vianna (2002:62), que retomam as formulações de Paine (1977:80-86) e, valendo-se da figura da governanta como tutora, propõem que a tutela implica necessariamente certa infantilização daqueles que são o seu objeto, ao que o matronazgo recordaria que a esta infantilização corresponde uma 'maternalização' da gestão" (Lugones 2012:213). Para outras contribuições neste sentido, ver o artigo fundamental de Vianna e Lowenkron sobre processos de engendramento entre gênero e Estado, bem como os artigos apresentados nesta coletânea, publicados pelo Cadernos Pagu (2017). 


\section{Referências bibliográficas}

AGUIÃO, Silvia. 2014. "Fazer-se no Estado": uma etnografia sobre o processo de constituição dos ' $L G B T^{\prime}$ como sujeitos de direitos no Brasil contemporâneo. Tese de Doutorado em Ciências Sociais, Instituto de Filosofia e Ciências Humanas, Universidade Estadual de Campinas.

BATESON, Gregory. 1972. Steps to an ecology of mind: Collected essays in anthropology, psychiatry, evolution, and epistemology. Chicago: University of Chicago Press.

BOLTANSKI, Luc \& THÉVENOT, Laurent. 1991. De la justification: les économies de la grandeur. Paris: Éditions Gallimard.

BROWN, Wendy. 1992. "Finding the Man in the State". Feminist studies, v. 18, n. 1:7-34.

CARSTEN, Janet. 2011. "Substance and relationality: blood in contexts". Annual Review of Anthropology, v. 40:19-35.

DEFENSORIA PÚBLICA DO ESTADO DO RIO DE JANEIRO. Falta de vagas em creches do Rio leva multidão à Defensoria Pública Rio de Janeiro, 22/01/2018. Disponível em: http:// www.defensoria.rj.def.br/noticia/detalhes/5496-Falta-de-vagas-em-creches-do-Rio-leva-multidao-a-Defensoria-Publica. Acesso em: 31/07/2019

FERNANDES, Camila. 2011. Ficar com: Parentesco, Criança e Gênero no cotidiano. Dissertação de Mestrado, Programa de Pós-Graduação em Antropologia - PPGA/UFF. Niterói.

. 2017. Figuras da causação: sexualidade feminina, reprodução e acusações no discurso popular e nas políticas de Estado. Tese de Doutorado em Antropologia, PPGAS-Museu Nacional, Universidade Federal do Rio de Janeiro (UFRJ).
FERREIRA, Letícia Carvalho de Mesquita. 2015. Pessoas desaparecidas. Uma etnografia para muitas ausências. Rio de Janeiro. Editora UFRJ.

FREIRE, Lucas. 2016. "Sujeitos de papel: sobre a materialização de pessoas transexuais e a regulação do acesso a direitos". Cad. Pagu [on-line], n. 48, e164813. Epub Oct 20.

FONSECA, Claudia. 1995. Caminhos da adoção. São Paulo: Cortez Editora.

FOUCAULT, Michel. 2000. Em defesa da sociedade: Curso no Collège de France (1975-1976), (trad. de Maria Ermantina Galvão). São Paulo: Martins Fontes.

G1. 2019. Prefeitura diz que Rio vai abrir 6 mil novas vagas em creches em 2019. Rio de Janeiro, 06/02/2019. Disponível em https://g1.globo.com/ rj/rio-de-janeiro/noticia/2019/02/06/ prefeitura-diz-que-rio-vai-abrir -mais-de-6-mil-novas-vagas-emcreches-em-2019.ghtml. Acesso em: 31/07/2019

HERZFELD, Michael. 1992. The social production of indifference: exploring the symbolic roots of western bureaucracy. Chicago: The University of Chicago Press.

LACERDA, Paula Mendes. 2015. Meninos de Altamira: violência "luta" política e administração pública. Rio de Janeiro: Garamond.

LOPES, Paulo Victor. 2016. Homens autores de Violência Doméstica: relações de gênero, formas cotidianas de governo e processos de formação do Estado. Tese de Doutorado em Antropologia, PPGAS-Museu Nacional, Universidade Federal do Rio de Janeiro (UFRJ).

LOWENKRON, Laura. 2015. O monstro contemporâneo: a construção social da pedofilia em múltiplos planos. Rio de Janeiro: EdUERJ. 
LUGONES, Maria Gabriela. 2012. Obrando en autos, obrando en vidas: formas y fórmulas de protección judicial en los tribunales prevencionales de menores de Córdoba, Argentina, a comienzos del siglo XXI. Rio de Janeiro: E-papers/LACED/Museu Nacional.

MITCHELL, Timothy. 2006. "Society, economy, and the state effect". The anthropology of the state: A reader, p. 169-186.

PIGNARRE, Philippe \& STENGERS, Isabelle. 2013. La sorcellerie capitaliste: pratiques de désenvoûtement. Paris: La Découverte.

SOUZA LIMA, Antônio Carlos. 2002. "Introdução: Sobre gestar e gerir a desigualdade: pontos de investigação e diálogo". In: A.C. de Souza Lima (ed.), Gestar e Gerir: Estudos para uma antropologia da administração pública no Brasil. Rio de Janeiro: Relume Dumará. pp. 11-22.

. 2012. "Apresentação Dossiê Fazendo Estado: O estudo antropológico das ações governamentais como parte dos processos de formação estatal". Revista de Antropologia, USP, v. 55, n. 2:559-564.

TEIXEIRA, Carla Costa \& SOUZA LIMA, Antônio Carlos. 2010. "A antropologia da administração e da governança no Brasil: área temática ou ponto de dispersão?". In: C.B. Martins \& L.F. D. Duarte (eds.), Horizontes das Ciências Sociais no Brasil: Antropologia. São Paulo: Anpocs. pp. 51-95.
VIANNA, Adriana de Resende Barreto. 2002. Limites da menoridade: tutela, família e autoridade em julgamento. Tese de Doutorado, Programa de PósGraduação em Antropologia Social, Museu Nacional, Universidade Federal do Rio de Janeiro.

. 2013. "Introdução: fazendo e desfazendo inquietudes no mundo dos direitos". In: Adriana Vianna (org.), O fazer e o desfazer dos direitos: experiências etnográficas sobre política, administração e moralidades. Rio de Janeiro: E-Papers. pp. 36-67.

VIANNA, Adriana de Resende Barreto \& FARIAS, Juliana. 2011. "A guerra das mães: dor e política em situações de violência institucional". Cadernos Pagu, n. 37:79-116.

VIANNA, Adriana de Resende Barreto. 2014. "Violência, Estado e Gênero: considerações sobre corpos e corpus entrecruzados" In: SOUZA LIMA, Antônio Carlos de; GARCIA-ACOSTA, Virginia (orgs.), Margens da violência. Subsídios ao estudo do problema da violência nos contextos mexicanos e brasileiros. Brasília: ABA pp. 209-237.

VIANNA, Adriana \& LOWENKRON, Laura. 2017. "Apresentação. Dossiê Gênero e Estado: formas de gestão, práticas e representações". Cadernos Pagu, n. 51:e175100. 
FIGURAS DO CONSTRANGIM ENTO: AS INSTITUIÇÕES DE ESTADO E AS POLÍTICAS DE ACUSAÇÃO SEXUAL

\section{Resumo}

O artigo explora como se arquiteta um discurso de acusação em torno da sexualidade feminina "irresponsável" no interior de instituições públicas. A discussão parte de etnografia realizada em creches públicas situadas num complexo de favelas da Zona Norte (RJ). Apresento as principais etapas de acesso às vagas na instituição, assim como as estratégias mobilizadas pelas famílias para conseguir uma vaga. Acompanho de que maneira algumas situações são conduzidas a partir de uma pedagogia do constrangimento, nas quais "esporros" públicos configuram um campo de tensão entre funcionárias e mulheres usuárias dos serviços. A relação entre mulheres é marcada pela ambivalência de uma ação administrativa que, ao mesmo tempo em que acolhe as demandas pelo cuidado das crianças, é feita de censuras e constrangimentos morais. Ao final, discuto a presença de um Estado feminino, uma ação que mescla qualidades de cuidado ao lado de expedientes de cobrança e responsabilização.

Palavras-chaves: mulheres, reprodução, sexualidade, Estado, acusação.
FIGURAS DEL CONSTREÑIMIENTO: LAS INSTITUCIONES DEL ESTADO Y LAS POLÍTICAS DE ACUSACIÓN SEXUAL

\section{Resumen}

El presente artículo busca demostrar cómo se construye un discurso de acusación en torno a la sexualidad femenina "irresponsable" dentro de instituciones públicas. La discusión parte de una etnografía realizada en guarderías públicas localizadas en un complejo de favelas de la Zona Norte de la ciudad de Rio de Janeiro. Presento las principales etapas de acceso a las vacantes en la institución, las estrategias y las batallas movilizadas por las familias para conseguir una vacante. Acompaño de cual manera algunas situaciones son conducidas por una "pedagogía del constreñimiento", en las que escenas de "esporas" públicas configuran un campo de tensión entre funcionarias y mujeres usuarias de los servicios. La relación entre mujeres es marcada por la ambivalencia de una acción administrativa que, al mismo tiempo que acoge las demandas de cuidado de los niños, se hace a través de censuras y constreñimientos morales. Al final, analizo la presencia de un "Estado femenino", una acción que mezcla calidades de cuidado al lado de prácticas de cobranzas y responsabilización.

Palabras clave: mujeres, reproducción, sexualidad, Estado, acusación. 
FIGURES OF CONTAINMENT:

STATE INSTITUTIONS AND SEXUAL ACCUSATION POLICIES

\begin{abstract}
This article demonstrates how a discourse of accusation and accountability on "irresponsible" female sexuality is structured within public institutions. The discussion is based on an ethnography of public day-care in a favela complex in the Northern Zone of Rio de Janeiro. I present the main steps for obtaining access to vacancies in the nursery, and the strategies and battles waged by the families trying to get a place. I follow how some situations are driven
\end{abstract}

by a "pedagogy of embarrassment", in which scenes of negative, public lambasting and moral lessons make up a field of tensions between employees and the women who use the service. The relation between women is marked by the ambivalence of administrative acts that, while tending to the needs of children, is shot through with censure and moral humiliation. In the end of the article, I analyse the presence of a "Female state", an action that mixes loving qualities commonly related to femininity with the practice of coercion and the admonition of bodies.

Key words: women, reproduction, sexuality, State, accusation. 